\title{
Future Generation Adequacy of the Hungarian Power System with Increasing Share of Renewable Energy Sources
}

\author{
Agnes Gerse \\ Department of Energy Engineering, Budapest University of Technology and Economics, \\ MAVIR ZRt., Budapest, Hungary \\ e-mail: gerse@mavir.hu
}

Cite as: Gerse, A., Future Generation Adequacy of the Hungarian Power System with Increasing Share of Renewable Energy Sources, J. sustain. dev. energy water environ. syst., 3(2), pp 163-173, 2015, DOI: http://dx.doi.org/10.13044/j.sdewes.2015.03.0013

\begin{abstract}
The power generation sector is expected to undergo substantial changes in Hungary in the near future due to the decommissioning of several large units reaching the end of their lifetimes in parallel to the projected increase of renewable electricity generating capacity. In addition to the traditionally widely used deterministic adequacy assessment methods, a probabilistic approach has a great importance in case of technologies with different capacity credits. An analytical country-specific adequacy assessment model enabling the probabilistic modelling of wind power plants was developed and applied to generating capacity forecasts for Hungary. Model parameters were estimated using multi-annual production, plant availability and hourly system demand data. Adequacy indicators obtained from the model clearly show increasing reliance on imported electricity in the absence of investments in new generating capacity.
\end{abstract}

\section{KEYWORDS}

Generation adequacy assessment, Security of supply, Reliability, Demand, Power generation, Renewable Energy Sources (RES), Prospective system analysis.

\section{INTRODUCTION}

Generation adequacy is a key element of electric system reliability, ensuring that there is sufficient installed capacity in the power system to meet the electric load [1], including reserve capacity to perform corrective and preventive maintenance, as well. At present, a wide range of generation adequacy assessment methodologies and adequacy metrics are used in Europe [2], that were originally developed for thermal and hydro dominated systems. However, there is a growing expectation for the improvement of methodology due to the increasing share of RES production of highly stochastic nature. In parallel with RES integration, the absence of investments and premature decommissioning of existing units can lead to a shortfall in conventional generating capacity, as well. Therefore electricity transmission system operators have a very important role in contributing to the monitoring of security of supply in order to provide relevant information for decision-makers.

Despite of the considerable work done on the development of generating capacity reliability assessment, the dominant practice has been to use deterministic approach with deterministic adequacy criteria, such as a reserve capacity equal to a percentage of the expected load. Recently, probabilistic methods have gained more and more importance because of their ability to respond to stochastic factors influencing system reliability. Probabilistic criteria and indices include LOLP, LOLE, LOEE, EENS and EUE. Both 
analytical approach (mathematical models using mathematical solutions) and simulation techniques are applied for the evaluation of reliability indices [3].

In the last two decades, new methods were introduced to enable the capacity adequacy evaluation of power systems with a significant share of wind power plants. Because of the limited availability of normalised wind power production time series, site-specific wind data simulation models were developed and validated consisting of wind speed models and wind turbine generation models based on power curves [4]. As a simplification, a multi-state approach was proposed for wind farms providing sufficient accuracy by considering a large number of discrete output states [5,6]. Based on the multi-state approach, D'Annunzio and Santoso [7, 8] used multiple years of wind power output data to construct the capacity outage individual probability table for wind power plants. More recently, research has focused on the capacity credit calculation methods of wind power plants $[1,7,9]$.

In this paper, the multi-state representation is integrated into a generation adequacy assessment model elaborated Hungarian power system. Despite of the limitations of a one-country model, which should be kept in mind when considering the increasing role of cross-border exchanges, it can provide a substantial contribution for prospective analysis at national level for quantifying the reliance on imported electricity.

\section{SYSTEM CHARACTERISTICS, ADEQUACY CRITERIA}

Since the paper presents a country-specific adequacy assessment model, the main system characteristics and adequacy criteria are briefly summarized prior to the description of methodology.

The present electricity generation mix of Hungary is dominated by nuclear and thermal power plants. The power generation portfolio consists mostly of large power plants (with a generating capacity above $50 \mathrm{MW}$ at each plant), the majority of them were commissioned before 1990. From the beginning of the 2000s, a significant share of power capacity addition was small-scale CHP to supply local heat demand (district heating, industry, public institutions, etc.).

The main country statistics of 2012 are summarised in Table 1. Almost half of the domestic electricity production came from nuclear power (Paks Nuclear Power Plant). Other power plants using fossil fuels (mostly gas and lignite) supplied more than $40 \%$.

Table 1. Capacity and production data of Hungary (2012) [11]

\begin{tabular}{ccccc}
\hline & $\begin{array}{c}\text { Net generating capacity } \\
\text { (as of 31 December }\end{array}$ & Net annual production \\
& \multicolumn{2}{c}{ 2012) } & & \\
\hline Nuclear & 1,892 & 20.7 & 14.8 & 46.4 \\
Lignite & 740 & 8.1 & 4.8 & 15.1 \\
Hard coal & 294 & 3.2 & 0.8 & 2.5 \\
Gas & 5,229 & 57.2 & 9.0 & 28.2 \\
Oil & 410 & 4.5 & 0.1 & 0.3 \\
Hydro & 56 & 0.6 & 0.2 & 0.6 \\
Wind & 329 & 3.6 & 0.7 & 2.2 \\
Solar & 0.4 & 0.0 & 0.0 & 0.0 \\
Biomass & 189 & 2.1 & 1.5 & 4.7 \\
\hline Total & 9,139 & 100 & 31.9 & 100 \\
\hline
\end{tabular}


Because of geographical constraints, hydro power plants (all of them run-of-river, without storage capability) have a marginal role in domestic power generation. However, non-hydro RES production has a growing importance due to the commitment to sustainability. Considering the moderate wind [10] and solar generating potential of Hungary, RES production is based mostly on biomass, including biomass co-firing in coal fired power plants. The net wind generating capacity reached $329 \mathrm{MW}$ by the end of 2012. Solar PV installations have a negligible total generating capacity at the moment. (The vast majority of solar PV generation is connected to the grid as embedded generation.)

As a well-interconnected country, cross-border resources can provide a significant contribution to the electricity supply of Hungary subject to availability, heavily influenced by market conditions. Hungary has been a net importer of electricity for several years. Recently, a significant increase in electricity import has been observed. In addition to the $31.9 \mathrm{TWh}$ of domestic generation, $8 \mathrm{TWh}$ of electricity was imported in 2012 in order to cover the total consumption of $39.9 \mathrm{TWh}$. Net peak load of the system reached 6,016 MW in 2012, while the minimum of load was 2,586 MW.

After liberalisation of the electricity market, there is no more centralized capacity expansion planning in place in Hungary. However, mid- and long-term generation adequacy assessment reports are published by the transmission system operator on a regular basis. This adequacy assessment is based on a deterministic methodology, calculating system capacity balances for the peak load and assessing the level of expected remaining capacity. According to the former UCTE methodology, remaining capacity is the excess capacity above the forecasted peak load, taking into account expected unavailable capacity, outage, maintenance and system operation reserve.

In addition to the deterministic adequacy assessment approach, also a probabilistic generation adequacy standard exists: a LOLP based security of supply criterion is stated by the Grid Code. According to that criterion, LOLP cannot exceed $1 \%$ at any time. No methodology is specified by the Grid Code (e.g. clarification on the assessment of cross-border resources, capacity credit of wind power plants). Usually the results of a LOLP calculation for the projected annual peak loads are presented in the generation adequacy reports.

As shown by Figure 1 prepared using past retrospective capacity balances of 2011 , the most constrained months are the summer months. Therefore mid- and long-term probabilistic adequacy analysis cannot be limited to the expected winter peak loads.

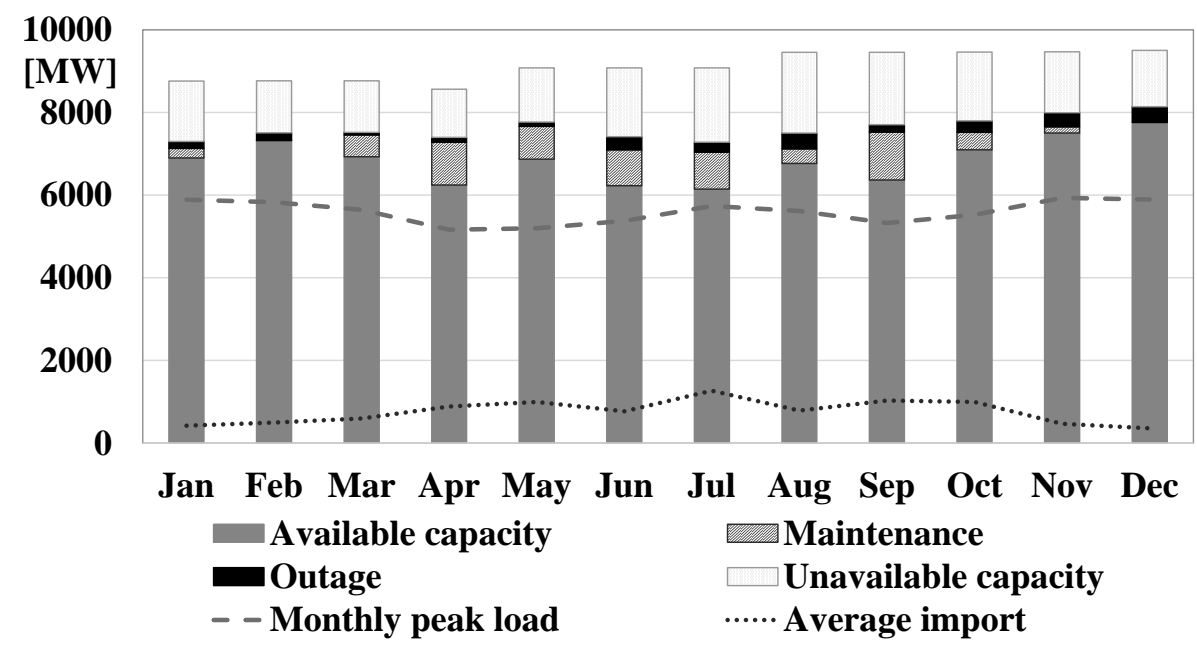

Figure 1. Monthly peak load vs. available net generating capacity in 2011 [12] 


\section{THE ADEQUACY ASSESSMENT MODEL}

An adequacy assessment model was developed in order to enable an extended probabilistic adequacy assessment taking into account RES with weather-dependent generation patterns, constraints resulting from maintenance as well as co-generation (CHP). The model can be applied for the calculation of different adequacy indicators: LOLP, LOLE (h) and LOLE (d).

\section{Supply side}

In the adequacy assessment model, net generating capacity is divided into the following categories: large conventional power plants, hydro power plants, wind power plants and other generating capacity (including small-scale CHP and solar PV generating capacity). Adequacy indicators are computed using an analytical method. Depending on the power plant categories, two-state models, multi-state models and aggregated firm capacity are used for the calculation of COPT.

Large conventional power plants. Large power plants with a nominal generating capacity of above $50 \mathrm{MW}$ are modelled per unit using a two-state model. In the case of existing units, FOR and maintenance requirements were estimated on the basis of past plant availability data (period of 1990-2008) and retrospective system balances [12]. For prospective analysis, assumptions on the plant availability data of projected new units have to be made, as well.

Depending on the technology, the temperature sensitivity of the output power and the effects of the heating period were also considered. (In Hungary, heating period is usually between 15 October and 15 April.) De-rated capacities were assumed for a number of CHP CCGT units in the summer months, since these can be operated with auxiliary cooling only when heat demand is low. Beyond that, the available generating capacity of non-CHP units is also influenced by ambient air temperature due to changes in gas turbine inlet air temperatures, cooling water temperatures, etc. In order to reflect these seasonal effects, nominal net generating capacities were multiplied by factors expressing the ratio of available and nominal capacity. These factors were estimated on a monthly basis based on past plant operation data.

Hydro power plants. For the assessment of the relatively small total generating capacity of run-of river hydro power plants, average monthly capacity factors can be used. These capacity factors can be calculated from past monthly production data [11]. Table 2 contains average monthly values for period 2002-2009, for wet, average and dry years.

Table 2. Average monthly capacity factors of Hungarian hydro power plants

\begin{tabular}{ccccccccccccc}
\hline & Jan & Feb & Mar & Apr & May & Jun & Jul & Aug & Sep & Oct & Nov & Dec \\
\hline Dry year & 0.23 & 0.11 & 0.13 & 0.10 & 0.28 & 0.13 & 0.30 & 0.24 & 0.20 & 0.40 & 0.38 & 0.34 \\
Average year & 0.36 & 0.37 & 0.22 & 0.42 & 0.47 & 0.41 & 0.46 & 0.42 & 0.46 & 0.48 & 0.43 & 0.42 \\
Wet year & 0.43 & 0.47 & 0.34 & 0.6 & 0.56 & 0.58 & 0.53 & 0.58 & 0.53 & 0.58 & 0.49 & 0.46 \\
\hline
\end{tabular}

Wind power plants. In order to assess the weather-dependent production patterns of wind power plants, a multi-state model was elaborated based on the approximate method proposed by D'Annunzio and Santoso [7, 8]. This method assumes that wind production can be properly modelled by a large number of discrete output states (partial capacity 
outage states) for adequacy assessment purposes. Instead of using synthetic data, the method is based on power output data.

The 15-minute resolution time series of total wind production in Hungary were collected as input from the years 2011 and 2012. Because of the intra-annual increase of the total installed wind generating capacity, time series were normalised and load factors were calculated. As an approximation, the load factor time series can be used for projected higher net generating capacities, but limitations (e.g. smoothing effect, influence of geographical distribution) should be kept in mind. In addition, aggregated on-line measurement data are also subject to errors, effects of maintenance, outages, trial runs under commissioning period, etc.

The multi-state representation of wind (Table 3) uses a load-factor resolution of 0.02 , considering 51 capacity outage states. (This resolution is equivalent to $6.48 \mathrm{MW}$ in case of the net installed capacity at the end of 2012.)

Table 3. Multi-state representation input data for wind power plants

\begin{tabular}{cc}
\hline $\begin{array}{c}\text { Capacity outage state } \\
\text { load factor } \\
(-)\end{array}$ & $\begin{array}{c}\text { Individual } \\
\text { probability } \\
(-)\end{array}$ \\
\hline 0.00 & 0 \\
0.02 & 0.000228 \\
0.04 & 0.000855 \\
0.06 & 0.002280 \\
0.08 & 0.003220 \\
0.10 & 0.003434 \\
$\ldots$ & $\ldots$ \\
0.90 & 0.040099 \\
0.92 & 0.045172 \\
0.94 & 0.052596 \\
0.96 & 0.061431 \\
0.98 & 0.084374 \\
1.00 & 0.155324 \\
\hline
\end{tabular}

Solar power plants. Due to the negligible present total net generating capacity, there are no aggregated online measurement data available for analysis. As a simplified approach, hourly production time series were estimated and taken into account on the basis of 2011 irradiation data. This approach can be justified by the moderate development targets (see Table 4).

\section{Capacity Outage Probability Table (COPT)}

COPT values express the cumulative probability $P(X \geq x)$ of having a system capacity outage greater than or equal to $x$. Values of COPT can be computed using a recursive algorithm [8]. When adding the new two-state unit $i+1$ with FOR of $F O R_{i+1}$ and net generating capacity of $C_{i+1}$ to the system containing already $i$ units, the following formula can be used:

$$
P\left(X_{i+1} \geq x\right)=(1-F O R) \times P\left(X_{i} \geq x\right)+F O R \times P\left(X_{i} \geq x-C_{i+1}\right)
$$


In the case of multi-state modelling applied for wind power plants, considering $m$ partial capacity outage states with individual probabilities of $p_{j}$ and capacity outage states $C_{j}$, the capacity addition formula is as follows:

$$
P\left(X_{i+1} \geq x\right)=\sum_{j=1}^{m} p_{j} \times P\left(X_{i} \geq x-C_{j}\right)
$$

Since capacity outage states are given by load factors in Table 3, they need to be up-scaled according to the total net wind generating capacity to be considered.

In the model, capacity outage probability tables were calculated for large power plants, whose availability is described by a two-state model, and for wind power plants (considered as an aggregated multi-state unit) on a monthly basis. Unavailable capacity of hydro power plants, solar power plants and other small-scale units were taken into account as a fixed input.

\section{Demand side}

For the calculations presented here, past hourly system load time series were used, scaled up according to the forecasted annual demand. As well known, system load patterns exhibit annual, daily and weekly seasonality, and in addition to that, both long (e.g. economic framework) and short term effects (e.g. weathering conditions, calendar effects) have a strong influence on system load characteristics. For temperature sensitivity analysis purposes, also a statistical, multiple regression based load model is available.

The applicability of statistical models adjusted to present system load patterns will be very limited in case of a very long time frame; therefore new approach has to be elaborated in order to take into account the effects of demand side management, heat pumps, electric vehicles, etc., properly.

\section{PROSPECTIVE ANALYSIS}

In a liberalized market environment, the development of the power plant portfolio is an outcome of individual decisions taken by investors and power plant operators subject to market and regulatory framework. The expected technical lifetime of existing power generating assets can be indicative only for the expected time of decommissioning. Unfavourable market conditions and significant surplus capacity can lead to premature decommissioning or mothballing of units, as it can be observed in several European countries nowadays. In order to take into account the uncertainties, usually several scenarios are examined.

For prospective analysis, we considered the scenarios submitted by the Hungarian electricity transmission system operator for the ENTSO-E Scenario Outlook and Adequacy Forecast 2013-2030 (SO\&AF) report (Figure 2) [13]. The ENTSO-E SO\&AF report contains several scenarios for each member country. In Scenario A (conservative scenario), only firm new investments can be considered, while Scenario B is a best estimate scenario assuming that all necessary regulatory and economic incentives will be in place. It should be noted that considering the lead time required for thermal power plants, the year 2015 is very near. Due to delayed final investment decisions and/or cancellation of licensed projects, there are no large power plant units under construction in Hungary at the moment. This results in an identical net generating capacity forecast for Scenarios A and B in 2015. However, the 2020 forecasts reveal a large gap between the 
two capacity outlooks reflecting a conservative (firm capacity additions only) and a best estimate (necessary investments are in place) approach.

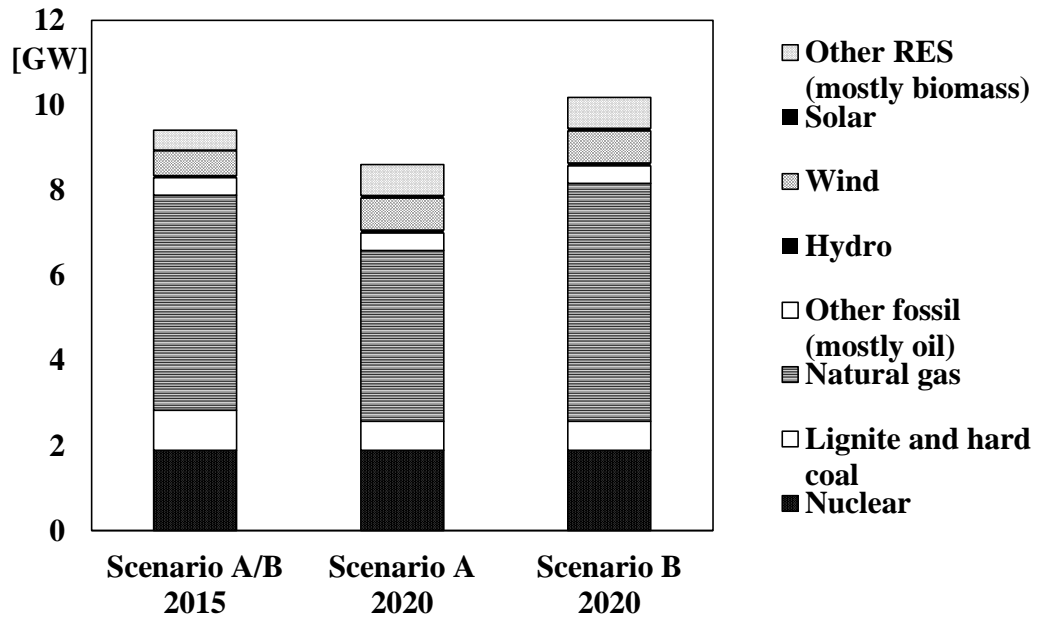

Figure 2. SO\&AF scenarios for 2015 and 2020

\section{Basic assumptions for the scenarios}

Concerning RES generating capacity, both Scenario A and B assess the expected power balances adjusted to the National Renewable Action Plans submitted by Hungary to the European Commission, as required by Article 4 of Directive 2009/28/EC (Table 4). This document is indicative only for Hungary, since it is subject to revision according to Government Decree 1491/2012. (XI.13.).

For the prospective analysis of thermal and nuclear generating capacity, the existing power plant portfolio, the expected decommissioning of power plants and possible new capacity additions should be assessed. In the SO\&AF scenarios, the existing power plant portfolio at the end of 2012 was taken as a basis. The decommissioning of large power plant units was assessed individually, based on the technical lifetime of power generating assets indicated in the licences issued by the regulatory authority. For smaller power plants, a decommissioning rate was estimated. For large-scale new capacity additions, the information on new projects included in the 2012 generation adequacy report prepared by the transmission system operator was used.

Table 4. Projected increase of RES generating capacity according to the NREAP of Hungary

\begin{tabular}{cccc}
\hline & $\begin{array}{c}2010 \\
{[\mathrm{MW}]}\end{array}$ & $\begin{array}{c}2015 \\
{[\mathrm{MW}]}\end{array}$ & $\begin{array}{c}2020 \\
{[\mathrm{MW}]}\end{array}$ \\
\hline Hydro & 51 & 52 & 55 \\
Geothermal & 0 & 4 & 57 \\
Solar & 0 & 19 & 63 \\
Wind & 330 & 577 & 750 \\
Solid & 360 & 377 & 500 \\
Biogas & 13 & 43 & 100 \\
\hline
\end{tabular}

Table 5 contains the total net generating capacity and number of two-state units assumed for each category. Smaller thermal power plants were modelled separately in an aggregated way, as described in the methodology; therefore their net generating capacity 
is not covered in Table 5. Units already mothballed were also not taken into account in the table. (As a result of unfavourable market conditions, several units with a lower thermal efficiency were mothballed recently, reaching a total unavailable capacity of 1.8 GW by the end of 2012.)

Table 5. Net generating capacity and number of power plant units represented by two-state model

\begin{tabular}{ccccccc}
\hline & \multicolumn{2}{c}{$\begin{array}{c}\text { SO\&AF 2015 } \\
\text { Scenario A and B }\end{array}$} & \multicolumn{2}{c}{$\begin{array}{c}\text { SO\&AF 2020 } \\
\text { Scenario A }\end{array}$} & \multicolumn{2}{c}{$\begin{array}{c}\text { SO\&AF 2020 } \\
\text { Scenario B }\end{array}$} \\
\hline & {$[\mathrm{MW}]$} & units & {$[\mathrm{MW}]$} & units & {$[\mathrm{MW}]$} & units \\
\hline Nuclear & 1,892 & 4 & 1,892 & 4 & 1,892 & 4 \\
Lignite & 850 & 5 & 680 & 3 & 680 & 3 \\
Hard coal & 90 & 3 & 0 & 0 & 0 & 0 \\
Natural gas & 2,816 & 17 & 2,159 & 16 & 3,498 & 19 \\
Oil & 407 & 3 & 407 & 3 & 407 & 3 \\
Other & 80 & 2 & 130 & 3 & 80 & 2 \\
\hline Total & 6,135 & 34 & 5,268 & 29 & 6,557 & 31 \\
\hline
\end{tabular}

As described earlier, Scenarios A and B are identical for 2015, since these forecasts look only one year ahead that is negligible compared to the longer lead time of large thermal and nuclear investments. However, the thermal generating assumptions for the 2020 scenarios differ significantly in gas fired net generating capacity.

Scenario A reflects a pessimistic approach where already existing units that are expected to remain in operation until 2020 are only considered. Scenario B as a best estimate projection takes into account three further CCGT units with a total of 1,339 MW of net generating capacity. Various new gas fired CCGT projects were developed in the recent years including both green-field investment and CCGT-upgrade of existing conventional units, but final investment decisions are delayed due to unfavourable market conditions. It was assumed that three of these projects can be realised until 2020 in order to ensure a satisfactory level of national generation adequacy.

The assumptions for nuclear generating capacity are the same, since the existing units of Paks nuclear power station are expected to be decommissioned after 2030. Two units of the lignite fired Mátra power station can be retired before 2020 (reflected in both Scenario A and B), while no new lignite based project is considered at the moment.

\section{Results of probabilistic generation adequacy assessment}

Probabilistic generation adequacy analysis was done for the years 2015 (mid-term) and 2020 (long-term), both for Scenario A and B. A one-hour resolution model was used, containing hourly system load, average production of hydro power plants, and hourly aggregated production profile of solar PV generators, small-scale RES and non-RES power plants. For wind production and large power plant units, the COPT values were calculated on a monthly basis, considering maintenance and partially unavailable capacity due to seasonal effects, as well.

Table 6 compares the COPT calculation results for 2015 (Scenarios A/B) and 2020 (Scenarios A and B). Since the calculation was done on a monthly basis, only the probability values computed for December are shown in the table. As described earlier in the methodology, COPT values express the cumulative probability $P(X \geq x)$ of having a system capacity outage greater than or equal to $x$.

The probabilities of having a certain level of system capacity outage are determined by the total net generating capacity and its composition (share of variable generation, 
individual forced outage rates of the units). As shown in Figure 2, Scenario B, year 2020 has the highest net generating capacity, while Scenario A, year 2020 has the lowest installed capacity. The level of variable generation differs slightly: $580 \mathrm{MW}$ (Scenario A/B 2015) and $750 \mathrm{MW}$ (Scenario A/B 2020). As a result of all these influencing factors, the COPT values computed for Scenario B 2020 (largest net generating capacity) are the highest, while the probabilities for Scenario A/B 2015 (lower level of wind generating capacity) are the lowest.

Table 6. Capacity outage probability table

\begin{tabular}{cccc}
\hline $\begin{array}{c}\text { Capacity outage } \\
\text { [MW] }\end{array}$ & $\begin{array}{c}\text { Scenario A/B 2015 } \\
\text { probability } \\
P(X \geq x)\end{array}$ & $\begin{array}{c}\text { Scenario A 2020 } \\
\text { probability } \\
P(X \geq x)\end{array}$ & $\begin{array}{c}\text { Scenario B 2020 } \\
\text { probability } \\
P(X \geq x)\end{array}$ \\
\hline 0 & 1 & 1 & 1 \\
250 & 0.94702914 & 0.95807864 & 0.96291066 \\
500 & 0.72315155 & 0.82406386 & 0.84385956 \\
750 & 0.30692813 & 0.47417549 & 0.52752663 \\
1,000 & 0.11758156 & 0.16099380 & 0.23142160 \\
1,250 & 0.03350453 & 0.04680618 & 0.08121181 \\
1,500 & 0.00828225 & 0.01231138 & 0.02844538 \\
1,750 & 0.00178860 & 0.00243082 & 0.00711312 \\
2,000 & 0.00032328 & 0.00042170 & 0.00172182 \\
\hline
\end{tabular}

Based on the COPT data, annual LOLE (h) values and LOLP indices at the annual peak load were calculated, as shown in Table 7. (The LOLP indices are given for the hour of the annual peak load).

Table 7. LOLE (h) values and LOLP at the annual peak load

\begin{tabular}{ccc}
\hline Year/Scenario & LOLE (h) & LOLP \\
\hline SO\&AF 2015, Scenario A and B & 13.54 & $1.87 \%$ \\
SO\&AF 2020, Scenario A & 844.12 & $91.73 \%$ \\
SO\&AF 2020, Scenario B & 10.82 & $0.70 \%$ \\
\hline
\end{tabular}

The reliability indices can help to show to what extent the power system is supposed to rely on imported electricity in the three cases that were examined. Based on the adequacy indicators, a slight shortage of domestic generating capacity is expected by 2015, since the LOLP at the annual peak load (without import) exceeds the reference value of $1 \%$. However, more serious electricity import dependency is foreseen for 2020 if no domestic investments will take place. In case of the conservative capacity forecast Scenario A, both LOLE (h) and LOLP values for the year 2020 are extremely high. The LOLP value of near $100 \%$ suggests that the load is very likely to exceed the domestically available generating capacity at the annual peak time. Depending on the future evolution of demand and supply side, a close monitoring of the availability of imported electricity might be necessary.

\section{CONCLUSION}

Many external factors including economic, regulatory and policy framework affect mid- and long term generation adequacy. Despite of the limited opportunities to consider 
all these influencing factors, adequacy assessment models and adequacy indicators can provide essential information on possible future capacity shortages for decision-makers. The presented model was developed to enable country level mid- and long term generation adequacy analysis and the computation of related generation adequacy indicators. When applying the methodology to the Hungarian power system, it enables to take into account the capacity credit of the developing wind energy sources more properly. Two projections were analysed covering the years 2015 and 2020. Based on the adequacy indicators, a minor shortage of domestic generating capacity can be expected by 2015 . For 2020, a more serious import dependency is foreseen in the absence of investments in power generation.

As stated by the IEEE Task Force on the Capacity Value of Wind Power, the multistate model constructed from a histogram of the wind power output can be considered as an approximate methodology [1], since important factors like the seasonal and diurnal patterns of wind production, and the information on wind/load correlation are not addressed by the model. Despite these concerns, the use of this approach can be justified in the initial phase of RES development when a limited amount of data is available for probabilistic generation adequacy assessment.

\section{NOMENCLATURE}

$P \quad$ Individual probability of capacity outage states for multi-state units $\quad[-]$

$x \quad$ Capacity outage $\quad[\mathrm{MW}]$

$C \quad$ Net generating capacity (two-state units) or capacity outage state [MW] (multi-state units)

\section{Abbreviations}

$\begin{array}{lll}\text { CCGT } & \text { Combined Cycle Gas Turbine } & {[-]} \\ \text { CHP } & \text { Combined Heat and Power } & {[-]} \\ \text { COPT } & \text { Capacity Outage Probability Table } & {[-]} \\ \text { ENTSO-E } & \begin{array}{l}\text { European Network of Transmission System Operators } \\ \text { for Electricity }\end{array} & {[-]} \\ \text { EUE } & \text { Expected Unserved Energy } & {[\mathrm{MWh} / \mathrm{year}]} \\ \text { EENS } & \text { Expected Energy Not Supplied } & {[\mathrm{MWh} / \mathrm{year}]} \\ \text { FOR } & \text { Forced Outage Rate } & {[-]} \\ \text { LOEE } & \text { Loss of Energy Expectation } & {[\mathrm{MWh} / \text { year] }} \\ \text { LOLE } & \text { Loss of Load Expectation } & {[\mathrm{h} / \text { year, }} \\ \text { LOLP } & \text { Loss of Load Probability } & \text { also: d/year] } \\ \text { SO\&AF } & \text { Scenario Outlook and Adequacy Forecast } & {[-]} \\ \text { UCTE } & \text { Union for the Coordination of the } & {[-]} \\ \text { X } & \text { Transmission of Electricity } & {[-]} \\ & \text { Random variable representing the possible capacity } & {[-]}\end{array}$

\section{REFERENCES}

1. Keane, A., Milligan, M., Dent, Ch. J., Hasche, B., D’Annunzio, C., Dragoon, K., Holttinen, H., Samaan, N., Söder, L. and O’Malley, M., Capacity Value of Wind Power, IEEE Transactions on Power Systems, Vol. 26, No. 2, pp 564-572, 2011, http://dx.doi.org/10.1109/TPWRS.2010.2062543

2. CEER, Assessment of electricity generation adequacy in European Countries, http://www.ceer.eu/portal/page/portal/EER_HOME/EER_PUBLICATIONS/CEER_P 
APERS/Electricity/Tab3/C13-EES-32-03_Generation Adequacy Assessment Elec_10-Dec-2013.pdf, [Accessed: 06-March-2014]

3. Allan, R. and Billinton, R., Probabilistic Assessment of Power Systems, Proceedings of the IEEE, Vol. 88, No. 2, 2000, http://dx.doi.org/10.1109/5.823995

4. Billinton, R. and Bai, G., Generating Capacity Adequacy Associated with Wind Energy, IEEE Transactions on Energy Conversion, Vol. 19, No. 3, pp 641-646, 2004, http://dx.doi.org/10.1109/TEC.2004.827718

5. Karki, R., Hu, P. and Billinton, R., A Simplified Wind Power Generation Model for Reliability evaluation, IEEE Transactions on Energy Conversion, Vol. 21, No. 2, pp 533-540, 2006, http://dx.doi.org/10.1109/TEC.2006.874233

6. Billinton, R. and Gao, Y., Multistate Wind Energy Conversion System Models for adequacy assessment of Generating Systems incorporating Wind Energy, IEEE Transactions on Energy Conversion, Vol. 23, No. 1, pp 163-170, 2008, http://dx.doi.org/10.1109/TEC.2006.882415

7. D'Annunzio, C. and Santoso, S., Noniterative Method to approximate the Effective Load Carrying Capability of a Wind Plant, IEEE Transactions on Energy Conversion, Vol. 23, No. 2, pp 544-550, 2008, http://dx.doi.org/10.1109/TEC.2008.918597

8. D'Annunzio, C., Generation adequacy assessment of Power Systems with Significant Wind Generation, Ph.D Thesis, The University of Texas at Austin, Austin, 2009.

9. Amelin, M., Comparison of Capacity Credit Calculation Methods for Conventional Power Plants and Wind Power, IEEE Transactions on Power Systems, Vol. 24, No. 2, pp 685-691, 2009, http://dx.doi.org/10.1109/TPWRS.2009.2016493

10. Radics, K. and Bartholy, J., Estimating and modelling the Wind Resource of Hungary, Renewable and Sustainable Energy Reviews, Vol. 12, pp 874-882, 2008, http://dx.doi.org/10.1016/j.rser.2006.10.009

11.ENTSO-E, Country Data Packages, https://www.entsoe.eu/data/data-portal/countrypackages/, [Accessed: 06-March-2014]

12.ENTSO-E, System Adequacy Retrospect, https://www.entsoe.eu/publications/ adequacy-retrospect/, [Accessed: 06-March-2014]

13.ENTSO-E, Scenario Outlook and Adequacy Forecast 2013-2030, Brussels, Belgium, 2013., https://www.entsoe.eu/about-entso-e/system-development/system-adequacy-and-marke t-modeling/soaf-2013-2030/, [Accessed: 06-March-2014] 